\title{
Ranking and Analysis of Hospital Pay Equity
}

\section{INTRODUCTION}

The Lown Institute Hospitals Index (LIHI) is the first hospital ranking to create a holistic view of American hospitals, ranking them not only on patient outcomes, but also on rates of overuse and civic leadership, or commitment to social mission. LIHI aims to provide data to help hospitals be more accountable for improving the health and well-being of their patients and the communities they serve.

This paper focuses on pay equity, which is a component of the civic leadership category of the Lown Index. Pay equity is the ratio between the compensation of a hospital's chief executive officer (CEO) and the average wage of the hospital's non-executive, non-clinical employees. We believe our pay equity metric is important to include in our ranking for three reasons. First, inequity in pay contributes to inequality, which affects the health of communities. Second, the degree of pay equity is one reflection of a hospital's dedication to its social mission, which many hospitals define in terms of providing excellent care to patients while also attending to the health of their surrounding communities. Third, pay equity is increasingly seen as a measure of corporate responsibility in many other industries.

There is a growing gap between the pay of hospital executives and that of both clinical health care workers, such as surgeons and nurses, and non-executive, non-clinical health care workers, such as clerical, cleaning, and kitchen staff. Total CEO compensation at major U.S. hospitals rose 93 percent between 2005 and 2015, vastly outpacing wage growth of other health care workers. ${ }^{[1]}$ Rapidly increasing CEO pay in the U.S. exacerbates inequality, which has been linked to poor health in the U.S. and other countries. ${ }^{[2,3]}$ While high and rising hospital executive pay has garnered recent headlines, it is not widely seen as a component of the hospital's performance or relevant to its social mission.

Hospital boards set executive compensation on the basis of a variety of factors such as hospital revenue, number of beds, and complexity of a hospital's various holdings, 
which in addition to clinical sites of care can include investment portfolios and property. Research shows that hospital CEO compensation is not correlated with better patient care, outcomes, or the provision of community benefits. ${ }^{[4]}$

\section{BACKGROUND}

\section{DETERMINING HOSPITAL EXECUTIVE COMPENSATION}

Average total compensation of CEOs of hospitals in the U.S. was $\$ 685,363$ in 2017, placing most hospital executives in the top 5 percent of U.S. earners. ${ }^{\left[{ }^{[6]}\right.}{ }^{6]}$ In addition to base salary, total compensation may include bonuses, other benefits, and stock options. Bonuses generally make up a significant percentage of a hospital CEO's total compensation. The average hospital CEO bonus is 33.2 percent of base salary, but bonuses can sometimes equal more than twice the base pay. ${ }^{[7]}$ Hospital executives often receive such additional benefits as supplemental retirement plans, which have resulted in tax-deferred payouts sometimes as large as seven-figures. ${ }^{[8]}$ Additionally, CEOs are usually offered paid perks such as memberships to country clubs, housing allowances, and/or chauffeur services.

The compensation package of executives is set by a hospital's governing board of directors, who usually form a compensation committee. Board members are generally focused on revenue goals, and in the case of for-profit hospitals, the company's stock. Most boards employ consulting groups to review CEO salaries and benefits data at peer hospitals with similar missions, budgets, and geography. Hospitals often review competitor compensation information and then offer higher pay packages in order to appear competitive. This act of benchmarking contributes to a rising average executive pay by continually creating a higher baseline for subsequent pay negotiations. ${ }^{[9]}$

In addition to peer data, hospitals state that patient outcomes and quality of care measures are factors in determining how they reward CEOs. However, research has shown neither is correlated with CEO compensation. A 2013 Harvard School of Public Health study reported no link between nonprofit hospital CEO compensation and quality of care indicators such as mortality or readmission rates. CEO pay is also unrelated to the amount of charity care provided. ${ }^{\left[{ }^{43]}\right.}$ The study reported that higher CEO compensation was tied in some cases to the purchase of advanced technology and higher patient satisfaction scores, neither of which have been tied to better outcomes. Hospitals often use expensive technology and patient satisfaction scores as marketing tools to grow revenue. 
Another study found little connection between CEO compensation and patient outcomes unless the hospital ranked in the 90th percentile in such metrics as 30-day mortality for heart attacks, heart failure, pneumonia, and patients' perceptions of the treatment they received. ${ }^{[10]}$ Though the top performing hospitals paid executives more than peer hospitals, there was little correlation for hospitals with even slightly lower performance on patient outcomes.

The hospital characteristics most significantly correlated with higher CEO pay are a greater number of beds, urban location, and teaching status - which are all generally associated with greater hospital revenue. ${ }^{[4]}$ Though the recent shift towards a valuebased payment model in the U.S. has pressured some hospitals to begin incorporating executive rewards based on quality measures such as patient satisfaction, the majority of CEO pay incentives are still rooted in volume and revenue targets. ${ }^{[1]}$ Reporting from hospitals required by the Internal Revenue Service (IRS) shows that hospital executives are rewarded with pay raises or bonuses for actions that boost revenue such as increasing the number of surgeries, admissions, or outpatient visits, expanding buildings or programs (such as chemotherapy centers), recruiting specialists, and increasing use of technology (such as da Vinci surgical robots). ${ }^{[2]}$

\section{ACCOUNTABILITY OF HOSPITAL EXECUTIVE COMPENSATION}

Hospitals often justify tying CEO compensation to revenue targets with the phrase, "No margin, no mission." [13] In other words, revenue is what keeps the doors open. They argue further that a hospital CEO's job is difficult, time intensive, and requires extraordinary talent. Some hospital CEOs have cited back-to back meetings and juggling calendar priorities as the "hardest part" of their work days. ${ }^{[14]}$ Hospitals also say they must offer high compensation rates to attract and retain competent talent as executive roles become more complex with the rise in consolidation, mergers, and changes in payment models. ${ }^{[15]}$ Hospitals assert that this increasing complexity narrows the talent pool of eligible leaders, however there is a lack of research and data to support such claims.

As hospital executive compensation has risen, so has public scrutiny. Hospital employees have criticized pay disparities at their institutions and protested their hospital giving executives million dollar pay rewards while frontline workers struggle with understaffing and low wages. ${ }^{[16-19]}$ The recent COVID-19 crisis has thrown pay disparities into sharp relief, as health care workers ask if their CEO's compensation is justified while the hospital is laying off and furloughing essential staff despite the modest executive pay cuts some hospitals have implemented. ${ }^{[20,21]}$ 
Other critics have pointed to the link between rising executive pay and the burden of patient costs and medical debt. ${ }^{[22,23]}$ Some hospitals engage in aggressive debt collection for unpaid bills from low-income patients, sometimes even from their own employees. ${ }^{[24,25]}$ In some instances, all the revenue generated from suing patients has amounted to less than the amount of the CEO's pay increase in one year. ${ }^{[26]}$ Even if a hospital is struggling financially and needs to cut costs, executive salaries are generally unaffected, while patient medical costs go up and budgets for such patient services as home care suffer. ${ }^{[27]}$

\section{Executive Compensation at Nonprofit Hospitals}

Nonprofit hospitals collectively enjoy billions of dollars in tax breaks each year on the condition that they provide "community benefits". ${ }^{28]}$ The original intent of this Internal Revenue Service (IRS) provision was to provide hospitals with compensation for providing charity care to uninsured and impoverished patients but has since been expanded to include other means of benefitting community health, such as community building and education (see LIHI's "Community Benefits Report" for more information on hospital community benefits spending). Many hospitals provide significant community benefits, while others provide considerably less even as they continue to pay their executives high salaries.

The IRS studied 20 nonprofit hospitals in 2009 to identify if they were complying with IRS reasonable compensation guidelines. ${ }^{[29]}$ The results showed that even though many of the reported executive compensation amounts appeared to be high, the majority of hospitals used elements of the IRS rebuttal presumption procedure-which means hospitals used peer data and independent decision-makers to establish compensation. The study also found that CEO compensation rose with hospital revenue. Nonprofit hospital executive compensation rates have triggered calls from the U.S. Congress for the IRS to exert greater oversight. ${ }^{[30,31]}$ The Tax Cuts and Jobs Act of 2017 implemented a 21 percent excise tax on executive compensation that exceeds $\$ 1$ million for the top five paid personnel, though experts believe it will not lead hospitals to cut executive compensation. Many nonprofit hospitals are using loopholes, like split dollar loan arrangements, to avoid the new excise tax. ${ }^{[32]}$

Nonprofit hospitals argue they must compete for prospective executives with for-profit hospitals, which can usually offer higher compensation. Nonprofit hospitals generally consider for-profit hospitals to be peers when surveying compensation data, rather than using compensation practices of similar nonprofit organizations in other fields. ${ }^{[33]}$ Nonprofit hospitals compensate their CEOs roughly six times the average CEO pay of other nonprofit sectors. ${ }^{[34]}$ For example, the CEO and President of the American Red Cross, a national nonprofit with a revenue of $\$ 2.7$ billion, received $\$ 686,352$ in total compensation in 2017 . Compared to the CEO of St. Vincent's Medical Center Riverside, a catholic nonprofit hospital in Florida in the Ascension health system which has the same amount of revenue as the Red Cross, who made $\$ 3,553,809$ in compensation. 


\section{LIHI'S MEASUREMENT OF PAY EQUITY}

We believe there is an argument to be made for hospital CEOs to be accountable for both achieving revenue targets and realizing their hospital's social mission. A hospital CEO should be rewarded for improving the health and well-being of its local community, keeping its patients safe, and providing high-value care. The LIHI ratio of CEO compensation to average non-executive, non-clinical health care worker wages provides an opportunity to analyze pay practices and equity in the U.S. hospital sector.

Our pay equity metric also provides a window into a hospital's adherence to its social mission because it reflects the institution's commitment to the health and well-being of its workers and, by extension, the surrounding community. High CEO pay exacerbates inequality, and inequality is a proven driver of poor health. ${ }^{[2,3]}$ While there is no existing direct evidence as to whether or not inequities in hospital pay contribute to ill-health in communities, hospitals are the largest employers in many towns and cities, and even some states, and thus hospital worker wage levels could have a real effect on the economic prosperity of a community and its people.

\section{METHODOLOGY}

We obtained data about hospital worker wages from two sources. The Centers for Medicare \& Medicaid Services' Healthcare Cost Report Information System (HCRIS) provided information on hourly wages for most hospitals. For the 704 hospitals that had incomplete wage index information in HCRIS, we used Bureau of Labor Statistics estimates of wages for health care employees within those metropolitan and nonmetropolitan statistical areas. We included lower level staff such as clerical, kitchen, janitorial and medical records personnel, and excluded professional staff positions requiring a specialized degree, such as physicians and nurse practitioners.

We gathered data for CEO compensation from three sources. For nonprofit hospitals, we used IRS 990 Forms, which nonprofit entities are required to file. Information on for-profit, publicly-traded hospitals was obtained from the Securities and Exchange Commission Filings. And we gleaned information about public and government hospital CEO pay from public records. Since non-publicly traded, for-profit hospital executive compensation is not publicly available, we estimated CEO compensation for these hospitals using a regression model for bed size and hospital revenue. We likewise used a regression model to estimate $\mathrm{CEO}$ pay for those public hospitals for which we could find no public records. We also had to impute CEO pay for fewer than 250 nonprofit hospitals which did not report their CEO's compensation to the IRS. 
For hospitals within a health system, we distributed the system CEO salary among the constituent hospitals proportionate to the percentage of total revenue each hospital generated. We added the system CEO's prorated salary to the individual hospital's CEO salary and similarly prorated additional work time, then adjusted the full-time equivalent employment (FTE) to generate a figure we refer to in this paper as total hospital CEO compensation (THCC). We included system CEO salary because the compensation for the system CEO amounts to a tax on individual hospitals, where revenue is generated for the system. To create our pay equity ratio (PER), we estimated hourly wages for CEOs based on a 60-hour work week and then calculated a ratio of THCC to average non-executive, non-clinical worker wages for each hospital.

\section{RESULTS}

Table 1: Pay equity by hospital type

\begin{tabular}{|l|l|l|l|}
\hline Category of Hospitals & $\begin{array}{l}\text { Average of Total Hospital } \\
\text { CEO Compensation } \\
\text { (THCC) per Hour }\end{array}$ & $\begin{array}{l}\text { Average of the Average } \\
\text { Worker Wage per Hour }\end{array}$ & $\begin{array}{l}\text { Average Pay Equity } \\
\text { Ratio (PER) }\end{array}$ \\
\hline All Hospitals & $\$ 272.83$ & $\$ 30.50$ & $8.47: 1$ \\
\hline Nonprofit Hospitals & $\$ 257.99$ & $\$ 30.34$ & $7.98: 1$ \\
\hline For-Profit Hospitals & $\$ 350.97$ & $\$ 31.39$ & $11.06: 1$ \\
\hline Teaching Hospitals & $\$ 402.38$ & $\$ 34.80$ & $11.39: 1$ \\
\hline Non-Teaching Hospitals & $\$ 215.33$ & $\$ 28.59$ & $7.18: 1$ \\
\hline Urban Hospitals & $\$ 349.62$ & $\$ 33.91$ & $10.14: 1$ \\
\hline Rural Hospitals & $\$ 141.45$ & $\$ 24.66$ & $5.62: 1$ \\
\hline Large Hospitals & $\$ 447.33$ & $\$ 35.42$ & $12.65: 1$ \\
\hline $\begin{array}{l}\text { Medium and Small } \\
\text { Hospitals }\end{array}$ & $\$ 180$ & $\$ 27.90$ & $6.25: 1$ \\
\hline $\begin{array}{l}\text { Top 100 Ranked } \\
\text { Hospitals for Pay Equity }\end{array}$ & $\$ 60$ & $\$ 30.98$ & $1.97: 1$ \\
\hline $\begin{array}{l}\text { Bottom 100 Ranked } \\
\text { Hospitals for Pay Equity }\end{array}$ & $\$ 1,152$ & $\$ 35.21$ & $32.82: 1$ \\
\hline
\end{tabular}

There is considerable variation in CEO compensation across hospitals. The highest paid hospital CEO in 2017 made just over \$6 million at Mount Sinai Medical Center in Miami Beach, FL, while the lowest paid CEO made about $\$ 38,000$ at Transylvania Regional Hospital in Brevard, NC. About 55 percent of all hospitals paid their CEO more than $\$ 500,000$, and about 19 percent of hospitals paid their CEO more than \$1 million. Generally, the CEO of a health system is paid much more than the CEOs of the individual hospitals within that system. The average compensation for individual 
hospital CEOs was $\$ 685,363$ in 2017 , while the average compensation for health system CEOs was $\$ 2,734,584$. About 80 percent of health systems paid their CEO more than $\$ 1$ million. The top-earning health system CEO made $\$ 25,549,644$ at Banner Health, a nonprofit system based in Phoenix, AZ.

Just as there is variation in CEO compensation rates, there is also variation in the Pay Equity Ratio (PER) across hospitals. The average PER was 8.47. The highest ranked hospital for PER, Nemaha Valley Community Hospital in Seneca, KS, paid its CEO $\$ 70,507$, and had an average worker wage of $\$ 18.98$, leading to a 1.19 PER. The lowest ranked hospital for PER, Inova Fairfax Hospital in Falls Church, VA, paid its CEO $\$ 1,809,563$. Inova Fairfax makes up two-thirds of the revenue of the Inova Health System, which pays its CEO $\$ 15,600,777$. Therefore, an additional $\$ 10,398,627$ was added to the CEO compensation for Inova Fairfax for the hospital's proportion of the system's CEO pay. That brings the Inova Fairfax THCC to $\$ 12,208,190$. The hospital has an average worker wage of $\$ 38.93$, resulting in an 80.0 PER.

As shown in Table 1, our data supports previous research findings that higher CEO compensation is associated with large teaching hospitals located in urban settings. These hospitals not only have higher executive pay, they also tend to have above average pay disparity. The average pay disparity at large, urban teaching hospitals is double that of small and medium, rural, non-teaching hospitals.

Table 2: Pay equity by revenue

\begin{tabular}{|l|l|l|l|}
\hline $\begin{array}{l}\text { Hospitals with } \\
\text { revenue... }\end{array}$ & $\begin{array}{l}\text { Average of Total Hospital } \\
\text { CEO Compensation } \\
\text { (THCC) per Hour }\end{array}$ & $\begin{array}{l}\text { Average of the } \\
\text { Average Worker } \\
\text { Wage per Hour }\end{array}$ & $\begin{array}{l}\text { Average Pay Equity } \\
\text { Ratio (PER) }\end{array}$ \\
\hline$>\$ 10$ billion & $\$ 1,258.64$ & $\$ 44.98$ & $28.93: 1$ \\
\hline $\begin{array}{l}\$ 1 \text { billion- } \$ 10 \\
\text { billion }\end{array}$ & $\$ 485.78$ & $\$ 36.43$ & $13.55: 1$ \\
\hline $\begin{array}{l}\$ 500 \text { million- } \$ 1 \\
\text { billion }\end{array}$ & $\$ 283.66$ & $\$ 33.92$ & $8.52: 1$ \\
\hline $\begin{array}{l}\$ 100 \text { million- } \$ 500 \\
\text { million }\end{array}$ & $\$ 187.61$ & $\$ 29.59$ & $6.40: 1$ \\
\hline $\begin{array}{l}\$ 50 \text { million- } \$ 100 \\
\text { million }\end{array}$ & $\$ 116.77$ & $\$ 22.90$ & $5.21: 1$ \\
\hline$<\$ 50$ million & $\$ 80.75$ & $\$ 20.85$ & $3.96: 1$ \\
\hline
\end{tabular}

Large, urban teaching hospitals also have nearly ten times the revenue of small and medium, rural, non-teaching hospitals. As can be seen in Table 2, the greater the 
revenue of a hospital, the greater the amount the hospital spends on CEO compensation and the bigger the pay disparity is between its CEO and other employees.

\section{CONCLUSIONS}

CEO to worker wage ratios in the hospital sector are smaller than those at the largest publicly traded, for-profit companies in the U.S., including nearly 50 of the largest forprofit publicly traded companies in the healthcare sector, where pay disparities clock in at 226:1. Nevertheless, hospitals still exhibit significant pay inequities. ${ }^{[35]}$ The biggest pay disparities between hospital CEOs and non-executive, non-clinical workers are found at high-revenue, large, urban teaching hospitals. Furthermore, nonprofit hospital CEO pay is far higher than CEO pay in the general nonprofit sector, by a factor of nearly six. ${ }^{[34]}$

We believe there is a need for greater transparency in reporting hospital executive compensation and worker wages for both clinical and non-clinical staff. All types of hospitals, regardless of nonprofit status or membership in a system, should be required to disclose $\mathrm{CEO}$ and other top executives' compensation, as well as average worker wages for clinical and non-clinical employees. As institutions that are generally seen as dedicated to the public good, nonprofit hospitals should have to report specific reasons to support the pay level of executives. These policies would allow the government and communities to understand hospital pay disparities more easily and decide if the disparities are justified. 


\section{ABOUT THIS WHITE PAPER}

This white paper is part of a series analyzing specific metrics in the Lown Institute Hospitals Index. This paper was written by Julia Healey, Shannon Brownlee, and Vikas Saini. Valérie Gopinath, Paula Smith, and Vikas Saini led the data analytics for this project.

Suggested Citation: Healey, J., Brownlee, S., Saini, V. Ranking and Analysis of Hospital Pay Equity. Brookline, MA: The Lown Institute. 2020.

\section{METRICS ADVISORY COUNCIL}

We greatly appreciate the Lown Hospitals Index Metrics Advisory Council for lending their advice and expertise to assist in the creation of the Lown Index. The members of the MAC are listed below. Thanks to Merrill Goozner and Alan Weil, Editor-in-Chief of Health Affairs, who advised us on the Pay Equity metric in particular.

William B. Adams

Co-chair, Patient Council, Right Care Alliance

Kevin Barnett, DrPH, MCP

Senior Investigator, Public Health Institute

Andrew Bazemore, MD, MPH

SVP of Research and Policy, American Board of Family Medicine

David Bor

Chief Academic Officer, Cambridge Health Alliance

Candace Chen, MD, MPH

Associate Professor of Health Policy \& Management, Milken Institute School of Public Health, The George Washington University

Joanne M. Conroy, MD

CEO and President, Dartmouth-Hitchcock

Adam Elshaug

Professor of Health Policy, University of Sydney

Elmer Freeman

Executive Director, Center for Community Health Education Research and Service

Paul Glastris

Editor in Chief, the Washington Monthly 
Merrill Goozner

Editor Emeritus, Modern Healthcare

Paul A. Hattis, MD, JD, MPH

Associate Professor, Tufts University School of Medicine

Emma Hoo

Director, Pacific Business Group on Health

Jeffrey Levi

Professor of Health Policy and Management, George Washington University

Sara Rosenbaum, JD

Harold and Jane Hirsh Professor of Health Law and Policy, George Washington

University

Aaron Schwartz

Resident, Department of Internal Medicine, Brigham and Women's Hospital

Pritpal S. Tamber

Independent Writer, Researcher and Consultant

Gary J. Young, JD, PhD

Director, Northeastern University Center for Health Policy and Healthcare Research 


\section{REFERENCES}

1. Du, J.Y., A.S. Rascoe, and R.E. Marcus, The Growing Executive-Physician Wage Gap in Major US Nonprofit Hospitals and Burden of Nonclinical Workers on the US Healthcare System. Clinical Orthopaedics and Related Research ${ }^{\circledR}, 2018$. 476(10): p. 1910-1919.

2. Dean Baker, J.B., and Jessica Schieder, Reining in CEO compensation and curbing the rise of inequality. 2019, Economic Policy Institute.

3. Chokshi, D.A., Income, Poverty, and Health Inequality. JAMA, 2018. 319(13): p. 13121313.

4. Karen E. Joynt, M., MPH ; Sidney T. Le, BA; E. John Orav, PhD; Ashish K. Jha, MD, MPH, Compensation of Chief Executive Officers at Nonprofit US Hospitals. JAMA Intern Med, 2014.

5. Lown Institute Hospitals Index (LIHI). 2020; Available from: www.lownhospitalsindex.org.

6. Wage Statistics for 2017. Social Security Administration.

7. Bryant, M., CEO salaries at nonprofit hospitals up 93\% since 2005, in Healthcare Dive. 2018.

8. Benson, B., SERPs up! Hospital execs win big, in Crain's New York Business. 2012.

9. CLIFFORD, S., How Companies Actually Decide What to Pay CEOs, in The Atlantic. 2017.

10. Koepke, F., Bilak, Pollack, Chenoweth, Flannery, Seaman, CEO Compensation at Nonprofit Hospitals: Associations with Performance Measures. 2016, Truven Health Analytics; Mercer.

11. Loria, K., Salary Trends: How new demands are shaping CEO compensation, in Managed Healthcare Executive. 2019. p. 8-11.

12. Hancock, J., Hospital CEO Bonuses Reward Volume And Growth, in Kaiser Health News. 2013.

13. GUNDERMAN, R., Why Are Hospital CEOs Paid So Well?, in The Atlantic. 2013.

14. Paavola, A., 13 healthcare CEOs share the hardest part of their days, in Becker's Hospital Review. 2019.

15. SullivanCotter, Newly Released SullivanCotter Survey Results Indicate Industry Disruption and New Talent Requirements are Impacting Executive Pay, in Results from the 2019 Manager and Executive Compensation in Hospitals and Health Systems Survey. 2019: SullivanCotter Website.

16. Bauman, A., Beaumont CEO's compensation jumps $82 \%$, workers outraged over low wages, in Detroit Free Press. 2019.

17. Kacik, A., Highest-paid not-for-profit health system executives earn 33\% raise in 2017, in Modern Healthcare. 2019.

18. PERKES, C., Kaiser workers in O.C. protest 'excessive salaries' of hospital system's executives, in The Orange County Register. 2016.

19. Gooch, K., Cedars-Sinai employees accuse hospital of overpricing, unfair labor practices, excessive CEO pay, in Beckers Hospital Review. 2019. 
20. McCormick, C., Nurses union criticizes executive's pay in face of furloughs, in The Barnstable Patriot. 2020.

21. Wire, B., CEO pay at Tenet Healthcare, Kroger, other firms come under microscope as companies cut costs, in The Dallas Morning News. 2020.

22. Out-of-Pocket Costs Rising Even as Patients Transition to Lower Cost Settings of Care. 2019, TransUnion Healthcare.

23. Ashley Kirzinger, C.M., Bryan Wu, and Mollyann Brodie, Data Note: Americans' Challenges with Health Care Costs, in Kaiser Family Foundation. 2019.

24. CERULLO, M., Hospitals are some of America's toughest debt collectors, in CBS News. 2019.

25. Kliff, S., With Medical Bills Skyrocketing, More Hospitals Are Suing for Payment, in New York Times. 2019.

26. Reed, T., Why is healthcare so expensive? This Johns Hopkins surgeon might have the answers, in FierceHealthcare. 2019.

27. Dwyer, J., Immune to Cuts: Lofty Salaries at Hospitals, in The New York Times. 2011.

28. Sara Rosenbaum, D.A.K., Jie Bao, Maureen K. Byrnes, and Colin O'Laughlin, The Value Of The Nonprofit Hospital Tax Exemption Was \$24.6 Billion In 2011. Health Affairs, 2015. 34(7): p. 1225-1233.

29. IRS Exempt Organizations Hospital Study - Executive Summary of Final Report, I.R. Service, Editor. 2009.

30. Strom, S., Congress Questions the I.R.S. About Delays in Its Oversight of Nonprofit Hospitals, in New York Times. 2011.

31. Hancock, J., Grassley: Who Approved These Hospital CEO Bonuses?, in Kaiser Health News. 2013.

32. Bannow, T., IRS guidance on excise tax for executive pay leaves questions for hospitals, in Modern Healthcare. 2019.

33. SullivanCotter, The growing influence of for-profit pay practices on not-for-profit executive pay, in Becker's Hospital Review.

34. CEO Pay Trends in the Nonprofit World. 2018, Economic Research Institute.

35. LaCross, J., Dissecting the CEO Pay Ratio by Sector. 2020, Equilar. 